\title{
A Formação do Professor de Língua Estrangeira no Século X XJ: entre as antigas pressões $e$ os novos desafios
}

\author{
The Education of the Foreign Language Teacher in the \\ Twenty-First Century: BETWEEN OLD PRESSURES AND NEW CHALLENGES
}

\section{Luiz Carlos Balga Rodrigues*}

Resumo: Este trabalho pretende refletir sobre a atual formação do professor de língua estrangeira e sua capacidade para enfrentar as pressões e os desafios que a prática docente lhe impõe nos dias de hoje. Desde que a globalização se fez presente no cotidiano, no final do século XX, vemos aumentar as mobilidades, as trocas e as interações entre povos e culturas. $\mathrm{O}$ aprendizado de uma língua estrangeira tornou-se uma demanda cada vez maior e o "mercado das línguas", segundo as concepções de Bourdieu (1982) e Calvet (2002), expõe suas características e suas regras. Proliferam os cursos de idiomas, os testes de certificação de proficiência, a oferta desenfreada de material didático; discutem-se novas abordagens no ensino de línguas; surgem novos objetivos específicos. Como preparar o estudante de Letras para enfrentar as pressões do mercado e os novos desafios da prática docente? Cabe às faculdades de Letras repensarem a formação profissional e intelectual do futuro professor de língua estrangeira, não esquecendo as exigências do mercado, mas se preocupando sobretudo com o desenvolvimento de sua autonomia e a reflexão crítica de suas práticas.

Palavras-chave: Formação de professores de língua estrangeira. Ensino-aprendizagem de língua estrangeira. Prática docente reflexiva.

\footnotetext{
* Professor Adjunto de Letras Francesas da Faculdade de Letras da Universidade Federal do Rio de Janeiro (UFRJ). Doutor em Letras Neolatinas pela Universidade Federal do Rio de Janeiro (2008). Contato: balga@superig.com.br.
} 
Abstract: This paper aims to reflect on the current training of foreign language teachers and their ability to face the pressures and challenges that teaching practice imposes today. Since globalization has been present in the quotidian life at the end of the twentieth century, we see increasing mobilities, exchanges and interactions between peoples and cultures. The learning of a foreign language has become a growing demand and the "linguistic marketplace”, according to Bourdieu (1982) and Calvet (2002), exposes its characteristics and rules. Language courses, proficiency certification tests and didactic material proliferate all the time; new approaches in language teaching are discussed; new specific objectives emerge. How to prepare the students of Letters to face the pressures of the market and the new challenges of the teaching practice? It is up to the faculties of Letters to rethink the professional and intellectual education of the future foreign language teachers, not forgetting the demands of the market, but being mainly concerned with the development of their autonomy and the critical reflection on their practices.

Keywords: Foreign language teachers training. Foreign language learning and teaching. Reflective teaching practice.

\section{Introdução}

Desde o final do século XX, um substantivo se popularizou de tal forma que saiu dos jornais, das revistas especializadas e passou a fazer parte do dia a dia, de todas as rodas de conversação, ainda que muitos não soubessem definir muito bem o que ele queria dizer: globalização. O que o senso comum, porém, conseguiu captar de imediato foi tudo aquilo que viria a cercar esse termo e que, de certa forma, vemos se confirmar nesse início de século XXI: aumento das mobilidades, das trocas, das interações entre povos e culturas. Se isso afeta de modo evidente todos os setores da sociedade, afeta também necessariamente aquele profissional cujo objeto de estudo e de trabalho está no cerne desse processo: o professor de língua estrangeira. Se o conhecimento de uma língua estrangeira (doravante LE) representava, no passado, um diferencial, que tornava o seu detentor alguém 
reconhecidamente mais erudito e supostamente mais preparado para o mundo profissional, podemos dizer que, hoje, o preparo para o mundo profissional pressupõe o conhecimento de uma língua estrangeira e o diferencial pode ter sido deslocado apenas para o quantitativo de línguas que se dominam.

No Brasil, isso é facilmente comprovado pela quantidade de cursos de idiomas que proliferaram a partir dos anos 1990, bem como pelo número crescente de procura pelas certificações de proficiência. A corrida pelas vagas nos centros de línguas das universidades revela uma tendência de se tentar reduzir a grande deficiência que ainda parece existir no aprendizado de uma língua estrangeira no Brasil. No Centro de Línguas Aberto à Comunidade (CLAC-UFRJ), por exemplo, existem atualmente cerca de quatro mil alunos inscritos que buscam aprender as mais diversas línguas (inglês, francês, espanhol, italiano, alemão, russo, japonês, árabe e hebraico), inclusive clássicas (latim e grego).

O surpreendente é que a escola muitas vezes parece ainda não ter se dado conta da importância do estudo de uma língua estrangeira (LE), haja vista a baixíssima carga horária reservada a essa disciplina na organização curricular da maioria das escolas públicas e privadas brasileiras, ainda que os Parâmetros Curriculares Nacionais (PCN) (BRASIL, 1998) já houvessem apontado para a importância de se aprender uma LE, algo tido inclusive como um direito de todo cidadão, conforme manifestado na última Lei de Diretrižes e Bases (LDB), de 1996 (BRASIL, 1996), e na Declaração Universal dos Direitos Lingüisticos, patrocinada pela UNESCO e publicada pelo Centro Internacional Escarré para Minorias Étnicas e Nações e pelo PEN-Club Internacional, firmado em Barcelona, também em 1996. Os PCN, aliás, deixam claro que o aprendizado de uma LE não deve fazer parte de uma atividade extracurricular da escola, mas, sim, de uma obrigação das instituições de ensino.

A corrida pelo aprendizado de uma LE é tanta que seu ensino chamado - de forma tão criticada - de generalista parece ter perdido um pouco a força. Os cursos de idiomas, hoje, procuram não se limitar aos cursos tradicionais - que duram cinco ou seis anos - mas tendem a oferecer cursos mais rápidos, intensivos, voltados para um público específico. $\mathrm{O}$ ensino de línguas com objetivos específicos, que surgiu com toda força nos idos de 
1980, parece ter encontrado no mercado editorial e, sobretudo, no mercado cada vez mais forte dos cursos de idiomas, um grande aliado, já que estes o viram como uma forma mais rentável de oferecer o seu produto. As exigências do público que procura esse aprendizado não são as mesmas de antigamente: falar como um nativo ou saborear obras literárias na língua original deixaram de ser as únicas metas a serem alcançadas. Hoje, há diversos objetivos: aprender para viajar, aprender para usar a língua escrita e/ou falada no seu campo profissional específico, aprender simplesmente a ler. Aprende-se em função de suas próprias necessidades e, muitas vezes, é o aprendiz quem dita o ritmo do curso, e não o inverso. O ensino de língua estrangeira com objetivos universitários pode ser visto como o mais recente campo de trabalho para professores de LE, tendo em vista o aumento dos programas de mobilidade acadêmica, como o "Ciência sem Fronteiras", por exemplo. Este programa tem por meta a oferta de mais de cem mil bolsas de estudo no exterior. Os países que possuem acordos com o Brasil exigem certo perfil linguístico dos candidatos que englobe competências linguísticas e culturais, avaliadas por testes de proficiência. É necessário, então, repensar a política linguística vigente no Brasil para o ensino de LE, para que se torne condizente com a política de internacionalização das universidades.

$\mathrm{E}$ a formação de professores de LE em nossas universidades? Estariam nossos cursos preparando efetivamente nossos estudantes de Letras para o exercício da prática docente, com tudo que dela se espera em nossos dias?

Baseamos nosso trabalho não apenas na legislação vigente, mas também em entrevista que realizamos com seis professores recém-formados no curso de Licenciatura em Letras Português-Francês da UFRJ, que já estão no mercado de trabalho, atuando como professores de língua francesa e que serão identificados aqui por letras de A a F. Os professores A, B e C trabalham em escola regular (pública/particular) e cursos de idiomas. Os professores $\mathrm{D}$ e $\mathrm{E}$ trabalham apenas em curso de idioma, e o professor $\mathrm{F}$ trabalha em mais de um curso de idiomas e ministra aulas particulares.

\section{A Baixa Qualidade do Ensino de LE no Brasil}

Não se pode tratar da formação de professores de LE sem mencionar a já conhecida baixa qualidade do ensino de línguas em nosso país. Como 
num círculo vicioso, a má qualidade do ensino está associada à má formação do professor.

O ensino de LE nas escolas brasileiras - e não hesitamos em afirmar que essa situação também parece estar presente em muitos cursos de idiomas - tem sido alvo não só de críticas, mas de muitas preocupações, tendo em vista os resultados frustrantes que vêm apresentando. Pesquisas como a de Sandei (2005, p. 1) mostram que muitos alunos saem da Educação Básica "com uma competência lingüístico-comunicativa mínima que não lhes permite estabelecer diálogos curtos nem elaborar/compreender pequenos textos". Outros trabalhos já clássicos, como os de Almeida Filho (1992,1993), revelam que os professores possuem um domínio muito precário da língua que ensinam e que, muitas vezes, possuem um conhecimento bem superficial das teorias de ensino/aprendizado de línguas, atuando exclusivamente com base em suas próprias convicções e experiências.

Consolo, Martins e Anchieta (2009), por sua vez, mostram que um grande percentual de alunos formados em cursos de Letras, no Brasil, não atinge níveis de proficiência oral satisfatórios para o ensino das LE nas quais se graduaram, o que compromete, por conseguinte, a qualidade do ensino de LE no país.

Não se pode esquecer de outros fatores que também contribuem para o resultado negativo, já tratados por Moita Lopes (1996): turmas muito numerosas, carga horária inexpressiva, excesso de trabalho do professor, que não tem tempo suficiente para se dedicar ao preparo das aulas, falta de material didático básico e a própria baixa credibilidade no ensino de línguas na escola, seja por parte da comunidade escolar (alunos, pais, colegas, direção da escola), seja por parte da sociedade em geral.

Essa ideia tão difundida de que a formação do professor de LE no Brasil é precária parece bastante forte e é facilmente constatável nas secretarias dos cursos de idiomas, sobretudo daqueles que oferecem cursos privativos: não raro o aluno solicita um professor nativo, baseado no senso comum de que um nativo (ainda que sem formação pedagógica) é mais adequado do que um profissional de Letras para ensinar uma língua estrangeira.

Isso é algo que me revolta. Lá no [nome do curso] muitos alunos assistem à aula demonstrativa que eu dou, dizem que gostam da aula, 
mas quando ficam sabendo de algum professor nativo com tempo vago, pedem ao diretor para trocar de professor. Já perdi dois grupos por causa disso. O pior é que o nativo que está lá agora nem professor é. (Professor F)

A diretora do curso sempre usa a presença de professores nativos como um diferencial pra vender o curso. O pior é que as turmas mudam de professor toda hora. Os nativos vêm pra cá, ficam alguns meses e vão embora. Quando os alunos ficam irritados de mudar de professor toda hora, é que se dão conta de que é melhor um professor brasileiro. (Professor D)

A questão da má formação do professor não diz respeito apenas à sua formação linguístico-comunicativa, mas toca também à própria prática pedagógica. Esta não deve ser tratada apenas no momento em que os estudantes se dedicam à prática de ensino nas faculdades de educação, mas também nos primeiros anos de sua vida profissional, quando muitas vezes são desassistidos no próprio ambiente escolar onde trabalham. Nóvoa (2007, p. 14) deixa isso muito claro:

Como cuidamos dos jovens professores? O pior possível. Eles vão para as piores escolas, têm os piores horários, vão para as piores turmas, não há qualquer tipo de apoio. Eles são 'lançados às feras' totalmente desprotegidos. E nós fazemos de conta que o problema não é conosco. É um problema talvez do Estado, talvez de alguém, das autoridades, mas não um problema nosso. Mas este é, sim, um problema nosso e dramático da profissão. Porque se não formos capazes de construir formas de integração mais harmoniosas, mais coerentes desses professores, nós vamos justamente acentuar nesses primeiros anos de profissão dinâmicas de sobrevivência individual que conduzem necessariamente a um fechamento individualista dos professores. É um problema dramático da organização da profissão: o modo como nos organizamos na escola, como nos organizamos com os colegas e como integramos os jovens professores. Se não for possível resolver isso, haverá muita dificuldade em resolver muito dos outros problemas que temos pela frente. 
A experiência inicial, muitas vezes traumática, é constantemente relatada pelos professores recém-formados. É o momento em que esse professor constata sua formação deficiente (tanto linguística quanto teórica), se sente desamparado, já que, por estar longe da universidade, não conta com o apoio dos professores e orientadores e agora, na escola ou no curso de idiomas onde trabalham, contam ainda menos com o acompanhamento de um supervisor ou simplesmente com o auxílio de algum colega mais experiente.

Fiquei desesperada, professor. Quase trinta alunos na sala, numa indisciplina total. Ninguém me dava atenção. Eu não sabia o que fazer. Tinha preparado um exercício de revisão que nem deu tempo de corrigir e que, sinceramente, vi que não serviu pra nada. (Professor A)

Nunca ninguém [da administração do curso] foi assistir à minha aula. Ninguém pergunta o que eu fiz, o que eu dei. Eu posso fazer o que eu quiser, que não estão nem aí. (Professor C)

Às vezes me dá uma insegurança braba. Fico com medo de falar francês. Fico com medo de fazer muitos erros e os alunos perceberem. No curso então, meu medo é maior ainda. A maioria dos alunos conhece mais a França do que eu, que só fui uma vez. (Professor B)

Além de ser visto quase sempre como um profissional pouco preparado para a sala de aula, tendo em vista sua tão propalada incompetência linguístico-comunicativa e seu despreparo teórico, uma outra crítica que comumente se faz aos professores de LE seria a sua contumaz alienação. $\mathrm{O}$ professor de LE, muitas vezes, é visto como alguém mentalmente colonizado, que usa sua sala de aula para transmitir os valores culturais do colonizador, como alguém que simplesmente reduz o ensino de língua a questões puramente metodológicas, sem se dar conta de que, como diz Pennycook (1994, p. 301), "nenhum conhecimento, nenhuma pedagogia é neutra ou apolítica". É claro que o professor de LE é alguém que deve se preocupar não apenas em ensinar estruturas linguísticas, questionando a todo momento suas práticas pedagógicas, evitando reproduzir fiel e cegamente o livro didático. Segundo Leffa (2005, p. 212): 
O professor que pode ser substituído pelo livro ou pelo computador deve ser substituído. O professor não pode simplesmente reproduzir o que está no livro - ou ser apenas um corretor ortográfico para o aluno. O livro ou o computador não substitui o professor, mas, ambos, podem obrigá-lo a evoluir.

Até mesmo o Ministério e as Secretarias de Educação parecem ter se dado conta dessa situação e, hoje em dia, as orientações governamentais caminham no sentido de que a formação do futuro professor de LE deve ser iniciada desde sua entrada na graduação. É uma forma de levá-lo a refletir sobre o ensino e a aprendizagem a partir de seu próprio processo de formação. As novas grades de certos cursos de licenciatura em Letras, como os da UFRJ, passaram a incluir, desde 2010, disciplinas de Educação desde o primeiro período da graduação.

Segundo Albuquerque Costa e Marinelli (2008, p. 95-6), o ensino/ aprendizagem da língua estrangeira deve problematizar situações

que levem em consideração a formação acadêmico-científica, tecnológica, técnica, artística, literária, enfim, diferentes dimensões que passariam a orientar os eixos formadores dos programas de curso. $\mathrm{O}$ estímulo à pesquisa, à busca de soluções de problemas no âmbito da reflexão didático-pedagógica, de instrumentos de avaliação e autoavaliação, entre outras questões, traz para docentes e discentes o desafio de re-ver, ou seja, re-visitar as práticas existentes buscando novos caminhos e reflexões mais aprofundadas.

\section{A Formação do Professor de LE}

Parece-me que, ao falarmos da formação do professor de LE, devemos considerar sua formação intelectual (cultural) e sua formação profissional (técnica). Não quero aqui revalidar uma dicotomia, mas, ao contrário, aceitar ambas as formações como incontestavelmente necessárias ao professor de hoje.

Quando falamos de formação intelectual, falamos de um domínio do conteúdo (linguístico e literário) da língua que se ensina, de um 
conhecimento teórico que busque também a interdisciplinaridade ou transdisciplinaridade, tão defendidas atualmente, mas que ainda parecem distantes dos nossos cursos de Letras. Faltam na maioria de nossos cursos, por exemplo, as cadeiras de Filosofia, Sociologia, Antropologia, Ciência Política, História, História da Arte, que dariam a nossos estudantes bases teórico-conceituais tão importantes para o aprimoramento crítico dos novos profissionais. Não se trata aqui de uma apologia da formação generalista, já tão criticada nos nossos cursos de Letras, nem uma tomada de posição que lute contra a corrente da especialização, exigência tão atual quanto irreversível, haja vista a quantidade de campos de atuação que existem para o profissional de Letras, impossível de ser abraçada por um único indivíduo.

O que parece também estar por trás dessa visão ainda tão fortemente humanística das nossas faculdades de Letras parece ser facilmente explicado pelo conceito de capital cultural de Bourdieu (1994), sempre supervalorizado pelos professores, já que historicamente nos vimos distanciados do capital econômico. Esse capital cultural pode ser não apenas objetivado (nos livros lidos, nas obras de arte conhecidas, nos softwares dominados), mas também institucionalizado, ou seja, socialmente sancionado pelas instituições (através de diplomas, títulos, etc.). Todo esse capital cultural, todavia, só se tornará visível e produtivo através do seu capital social, ou seja, do conjunto das relações que esse profissional estabelecer com seus pares, sua rede de contatos, nas instituições onde esse professor é identificado (conhecido e reconhecido).

Ser um bom professor, porém, não significa simplesmente dominar o conteúdo da sua área de atuação, mas sobretudo saber o que fazer com aquele conteúdo que se domina, decidir que uso dará a ele, decidir a forma como deve ser transmitido o conhecimento que adquiriu e, dentro de uma perspectiva ainda mais moderna, ter a consciência de que o conhecimento se constrói e se troca e que não se considera pronto e acabado com a colação de grau. Parece-nos claro que somente com uma postura crítica diante das suas práticas o professor de LE poderá vir, um dia, a tocar aquilo que Bourdieu (1994) chamou de capital simbólico, que resulta do reconhecimento, por parte do outro, daquele capital cultural e social de que falamos acima, e que lhe permite ser visto como um agente diferenciado no seu espaço social.

É bastante elucidativo o que disse Luiz Antônio Marcuschi, no XXV Encontro Nacional dos Estudantes de Letras, na UFRJ, em 2004. Faz mais 
de dez anos que esse texto, "A formação intelectual do estudante de Letras", foi apresentado e, como podemos ver, ainda é bastante atual.

O intelectual não se caracteriza pela posse de um grande cabedal de conhecimentos, sejam eles quais forem, ou pelo domínio de muito conteúdo cultural, histórico e temático em sua área, mas por sua capacidade de ação autônoma, crítica e ética com o saber de que dispõe a partir da vivência que construiu em sociedade... A formação intelectual do aluno de Letras [...] [é] a formação de um cidadão capaz de agir na construção do conhecimento para atuar junto à sociedade. A formação intelectual é a formação para a competência e não para a simples competição no mercado. (MARCUSCHI, 2009, p. 11)

A formação intelectual do profissional de Letras deve ser, portanto, cada vez menos centrada na acumulação do conhecimento e cada vez mais focada no seu desenvolvimento crítico, na construção da sua autonomia, que o leve a buscar os melhores caminhos e as melhores soluções na sua prática cotidiana. A prática, aliás, deve ser sempre o foco da formação e das preocupações dos professores. Vejamos o que diz Nóvoa (2007, p. 14):

A formação do professor é, por vezes, excessivamente teórica, outras vezes excessivamente metodológica, mas há um déficit de práticas, de refletir sobre as práticas, de trabalhar sobre as práticas, de saber como fazer. É desesperante ver certos professores que têm genuinamente uma enorme vontade de fazer de outro modo e não sabem como. Têm o corpo e a cabeça cheios de teoria, de livros, de teses, de autores, mas não sabem como aquilo tudo se transforma em prática, como aquilo tudo se organiza numa prática coerente. Por isso, tenho defendido, há muitos anos, a necessidade de uma formação centrada nas práticas e na análise dessas práticas. [...] Não é a prática que é formadora, mas sim a reflexão sobre a prática. É a capacidade de refletirmos e analisarmos. A formação dos professores continua hoje muito prisioneira de modelos tradicionais, de modelos teóricos muito formais, que dão pouca importância a essa prática e à sua reflexão. Este é um enorme desafio para profissão, se quisermos aprender a fazer de outro modo. 
Percebemos nos professores recém-formados a perfeita consciência desse problema de que trata Nóvoa. Vejamos:

Queria preparar aulas diferentes, mais dinâmicas, mas acabo não fazendo por falta de tempo e também porque não sei como fazer. Tenho lido alguma coisa sobre perspective actionnelle, mas não sei como dar aula nessa abordagem. Pra falar a verdade, nem sei se minha aula é mesmo comunicativa. Muitas vezes, quando me dou conta, acabo fazendo como muitos professores meus faziam e minha aula cai no tradicional. (Professor B)

Acho que o que sempre me faltou bem no início da carreira foi alguém que assistisse às minhas aulas e dissesse: é isso mesmo, ou então, faça assim ou tente fazer assado. Comecei a dar aula e nunca mais ninguém analisou minhas aulas, sugeriu isso ou aquilo e aí, eu fiquei meio perdida. Fui tentando no tapa. Às vezes me pergunto se toda a teoria que aprendi está sendo aplicada. (Professor E)

Entendemos, como Marcuschi sugeriu no final do trecho anteriormente citado, que competência e competição não se confundem. A competição deve ser vista como decorrência de uma situação mercadológica, mas não deve ser a base de sua formação. Se não se pode mais pensar a universidade como um local de formação humanística nos cânones dos séculos XVIII e XIX, também não se pode partir do extremo oposto e fazer dela um mero treinamento para esse mercado competitivo, o que muito a empobreceria e a tornaria incapaz de desenvolver aquilo que deve ser sempre sua grande meta: a formação de massa crítica. Dito de outra forma: estudantes e futuros profissionais que não irão simplesmente reproduzir cegamente o que acontece à sua volta, mas refletir sobre aquilo que se lhe apresenta, fazendo de suas práticas um exercício contínuo de reflexão.

Uma situação que também parece rondar as faculdades de Letras é a visão que certas unidades dentro das universidades têm - sobretudo dos setores de línguas - de que somos necessariamente prestadores de serviços. Não é raro sermos procurados por faculdades da área médica ou tecnológica para que organizemos testes escritos e orais para seus alunos, que precisam 
de uma certificação de proficiência linguística para um intercâmbio no exterior. Nóvoa (2007, p. 11) referindo-se à escola, já havia se dado conta desse perigo:

Grande parte dos debates e das políticas educativas hoje tende a ver a escola como um serviço que se presta às famílias, às crianças, menos como uma instituição. O que é mais grave: a agenda comunitarista por um lado, a agenda liberal por outro e ainda a agenda da privatização tendem a ver a escola como um serviço que se presta a alguém e não como um lugar onde se institui a sociedade, a cultura, onde nos instituímos como pessoas, onde nos instituímos dos nossos direitos próprios, e conseguirmos, a partir daí, criar uma palavra livre, autônoma nas sociedades contemporâneas. É preciso recusar todas as tendências que apontam a escola como um serviço e afirmá-la como uma instituição.

É claro que tornar o estudante de Letras crítico não significa, porém, levá-lo a ignorar as exigências mercadológicas. E quando falo em mercado, não me refiro apenas ao conceito capitalista e/ou marxista, mas ao conceito de Bourdieu (1994) e Calvet (2002), de mercado das línguas, onde cada língua desempenha um papel, um status próprio e pode ser encarada como qualquer bem comercializável, com valores diferenciados. O interesse que o estudo de cada língua suscita está diretamente ligado não apenas às representações que o aprendiz tem sobre essa língua, mas também a seu potencial em termos utilitários. Utilidade, aliás, definida por esse mercado e tão incorporada por todos.

O exemplo do francês parece ser bastante interessante para ilustrar o que tratamos acima, sobre o caráter utilitário que esse "mercado das línguas" nos impõe. A chamada Reforma Capanema (Lei Orgânica do Ensino Secundário), promulgada em 9 de abril de 1942, talvez tenha sido o momento de maior valorização das línguas estrangeiras no currículo. Nesse período ocorreu a divisão do ensino secundário em dois ciclos: o ginasial (4 anos) e o colegial (3 anos). Este último era ofertado em duas direções a escolher: o curso científico (marcado pelo estudo das ciências) e o clássico (de formação humanística, intelectual). De acordo com Chagas (1957), o ginásio tinha como 
disciplinas obrigatórias o latim, o francês (ambos com 4 anos) e o inglês (3 anos); o colegial tinha o francês (1 ano), inglês e espanhol ( 2 anos), latim e grego ( 3 anos, no clássico). Quanto à carga horária, o latim tinha 8 horas semanais; o francês, 13; o inglês, 12 e o espanhol, 2; totalizando 35 horas semanais para o ensino de idiomas.

A primeira Lei de Diretrizes e Bases, publicada em 20 de dezembro de 1961, retirou a obrigatoriedade do ensino de LE no ensino fundamental e secundário, deixando a cargo dos estados a opção pela sua inclusão na grade curricular. Como o prestígio da língua inglesa aumenta justamente nesse período em que o ensino de língua estrangeira perde um pouco da importância de que gozava na esfera institucional, o pouco espaço que resta à LE passa a ser ocupado pela língua inglesa, em detrimento de outras línguas estrangeiras, como o francês e o espanhol. A partir dos anos 70 proliferam os cursos de inglês e, paralelamente, consolida-se o senso comum de que língua estrangeira não se aprende de forma eficaz na escola. O francês, desde então, começa a perder seu prestígio.

Até os anos 1950/1960, o francês era certamente a língua estrangeira mais estudada. A relação entre ser considerado culto e conhecer o idioma de Molière era inquestionável. Os anos 1970 mostram, ao contrário, uma queda vertiginosa do francês. $\mathrm{O}$ inglês, que progressivamente vinha ganhando terreno desde o fim da Segunda Guerra Mundial, se consolida no Brasil e no mundo, a partir dos anos 1960/1970, como a primeira língua estrangeira a ser estudada. O francês passa a ocupar a segunda posição. Muitas escolas (públicas e privadas) deixam de oferecer o francês em sua grade curricular; o cenário de recessão e inflação dos anos 1980/1990, aqui no Brasil, afugenta o público dos cursos de outros idiomas que não o inglês. Nesse período, a Aliança Francesa chega a fechar algumas filiais. O que se vê hoje, desde o início do século XXI, é uma retomada crescente do francês. Claro que já não se fala mais de rivalizar com o inglês. A questão é que o inglês deixou de ser um diferencial e passou a ser uma condição sine qua non no mercado de trabalho. $O$ francês se torna o diferencial, a segunda ou terceira língua estrangeira a ser aprendida. E isso não surge ao acaso: centenas de empresas francesas se estabelecem no Brasil; diversos convênios entre universidades francesas e brasileiras são firmados; programas de mobilidade estudantil proliferam e fazem da França um dos lugares de destino preferido dos estudantes brasileiros 
do "Ciência sem Fronteiras". Não é à toa que, fruto do trabalho de professores da Universidade de Lyon, é publicado, em 2011, o primeiro livro sobre ensino de língua estrangeira com objetivos acadêmicos, o Français sur Objectif Universitaire, de Chantal Parpette e Jean-Marc Mangiante. O francês se revitaliza em um momento em que se percebe, portanto, a utilidade de se estudar esse idioma, seja por razões acadêmicas, seja por razões profissionais. Essa revitalização, vale ressaltar, ainda não encontrou respaldo no sistema educacional, mas apenas nos cursos de idiomas. $\mathrm{O}$ francês não reencontrou seu espaço na educação pública, chegando mesmo a perdê-lo para o espanhol, desde a implementação da Lei 11.161/2005, que instituiu a oferta obrigatória (no ensino médio) e facultativa (no ensino fundamental) do ensino de língua espanhola.

Tenho dado muitas aulas particulares [...]. Impressionante, só na semana passada recebi uns três e-mails da associação de professores pedindo professor de francês pra vários cursos. Agora tem sempre gente querendo aprender francês. Eu queria dar aula em colégio, mas tem que esperar concurso, né? Colégio particular com francês que eu conheça, são poucos. No [nome do colégio], já entreguei o currículo, mas até agora nada. (Professor F)

\section{O Professor Crítico e Reflexivo}

Como se constrói, então, esse professor crítico e reflexivo? Quais seriam as competências esperadas para um bom professor de LE? Muitos pesquisadores já tentaram traçar o perfil do que seria um professor reflexivo. Dewey (1959), por exemplo, via na ação reflexiva três aspectos fundamentais: espírito aberto (para questionar e reavaliar constantemente sua prática, aceitando as críticas necessárias ao seu aperfeiçoamento), responsabilidade (consciência de que sua ação é fundamental na formação do aluno) e dedicação (o engajamento efetivo na sua ação educadora). Schön (1997), por sua vez, pesquisou sobre as etapas desse processo reflexivo e concluiu que ela ocorre antes, durante e depois da ação: desde o momento em que preparamos a aula, escolhemos a abordagem a ser utilizada, estabelecemos o conteúdo, até a forma como efetivamente se dá a aula, passando pela 
reflexão sobre certa dificuldade apresentada por determinado aluno, alguma situação inesperada, por exemplo.

Ser um professor reflexivo é, antes de qualquer coisa, ter um envolvimento com seu trabalho, de forma crítica e responsável, deixando de lado aquele comportamento puramente técnico, que enxerga o aluno como um mero participante na sala de aula, um ser idealizado, neutro, desprovido de uma realidade social específica. Certos cursos de idiomas parecem ser o lugar onde a figura do professor reflexivo menos se constrói. Nesses cursos, muitas vezes os professores, tão logo admitidos, parecem ser treinados para dar aula segundo as determinações da "empresa", usando o material didático muitas vezes produzido pelo próprio curso. Não há que se falar em reflexão. Muitos treinamentos desse tipo são realizados por pessoas que sequer têm formação pedagógica.

Lá no [nome do curso], professor, quem faz o treinamento é o próprio dono. Ele é formado em administração de empresas. Não estudou pedagogia, não é professor e dá aquela formação de um dia só, só pra ensinar a usar o método do curso. (Professor D)

Eles pedem pra gente usar apenas o livro do curso, pra não trazer nenhum material de fora. (Professor E)

Ser um professor reflexivo implica em saber identificar fatores que auxiliam ou dificultam o aprendizado de uma LE, como questões individuais, sociais, faixa etária dos alunos, local onde a língua é ensinada (escola, curso de idioma, universidade), objetivo desse aprendizado (leitura, prática oral e escrita). Não há como trabalhar esses fatores e considerar os alunos como uma massa homogênea, como parece ser a tendência de alguns cursos de idiomas. Ser crítico e reflexivo implica também em assumir riscos e responsabilidades, conforme Silva e Zeulli (2010, p. 53, grifos do original):

Parece fácil cruzar os braços diante das dificuldades: treinamento de capacitação em institutos de idiomas onde não há espaço para questionamentos, singularidades; metodologia própria da instituição a ser seguida, sem observância de características individuais dos alunos; 
pressão exercida pela escola no cumprimento do cronograma e programa; número de alunos em sala; nível de expectativa de conteúdo divergente daquele oferecido; exigências dos pais de alunos; dificuldade de adequação da abordagem pedagógica ao contexto em que a LE é ministrada; o material didático utilizado ou a falta do mesmo, bem como de outros recursos como, por exemplo, equipamento eletrônico e de mídia; carga horária insuficiente, entre outros problemas.

O bom professor de LE dos dias de hoje, além de uma postura crítico-reflexiva, deve ser possuidor de certas competências: competências inerentes a todo profissional da educação e competências específicas ao professor de LE. Perrenoud (2000) estabeleceu, aliás, as dez novas competências para ensinar, que devem ser observadas por todo professor nos dias de hoje: 1) organizar e dirigir situações de aprendizagem; 2) administrar a progressão das aprendizagens; 3) conceber e fazer evoluírem os dispositivos de diferenciação; 4) envolver os alunos em suas aprendizagens e em seu trabalho; 5) trabalhar em equipe; 6) participar da administração da escola; 7) informar e envolver os pais; 8) utilizar novas tecnologias; 9) enfrentar os deveres e os dilemas éticos da profissão; e, 10) administrar sua própria formação contínua.

Consolo e Porto (2011, p. 67) resumem muito bem a noção de competência desenvolvida por Perrenoud:

A capacidade do indivíduo de agir eficazmente em um determinado tipo de situação, apoiando-se em conhecimentos, sem, contudo, limitar-se a eles; é a faculdade de mobilizar recursos cognitivos, saberes, habilidades e informações, para solucionar, com eficácia, uma série de situações. Quando pensamos em competências devemos também lembrar que estas envolvem um compromisso social, ético e político dos professores no exercício de sua docência; e ainda, que tais competências são influenciadas por diferentes experiências, vivências e opções.

No caso do professor de LE, há outras competências que lhe são específicas. Almeida Filho (1993, p. 20) parece ser o autor que melhor detalhou 
essas competências. São elas: a) competência implícita (conjunto de crenças, intuições e experiências adquiridas); b) competência linguístico-comunicativa (o uso satisfatório da língua que se ensina); c) competência teórica (o conhecimento das teorias de ensino/aprendizagem); d) competência aplicada (a vivência dos conceitos teóricos no cotidiano da sala de aula); e) competência profissional (a consciência que o professor deve ter de seu papel formador, profissional e político).

A competência linguístico-comunicativa parece ser, em um primeiro momento, a que mais aflige o professor recém-formado. Os cursos de licenciatura em Letras geralmente certificam o professor para atuar na língua vernácula e em uma LE, e a maioria dos currículos apresenta uma carga horária bem maior de disciplinas ligadas à língua vernácula do que à língua estrangeira. Isso também contribui para a baixa proficiência na LE que estuda e compromete a sua competência linguístico-comunicativa em sala de aula e fora dela. Cabe ao professor, tendo consciência dessa deficiência, tentar sanála, por exemplo, por meio de um aperfeiçoamento linguístico, procurando, na medida do possível, uma formação continuada.

Ao lado da proficiência, cabe ao novo professor refletir constantemente sobre a sua prática pedagógica. Um dos grandes desafios do início de carreira é transpor a barreira entre a teoria e a prática. Muitos recém-formados (como já vimos pelos depoimentos acima transcritos) se sentem inseguros, não sabem o que fazer com toda a teoria que adquiriram nos cursos de graduação e nas disciplinas de educação.

Para que seja considerado um bom profissional na atualidade, o professor de LE, além do domínio da língua que se quer ensinar, deve procurar o domínio das novas tecnologias, a atualização didática, uma contínua autoavaliação de seu trabalho e o trabalho em equipe. É preciso ter a consciência de que não cabe apenas às instituições de ensino superior - por melhor que sejam - cuidarem da sua formação, assim como não cabe a elas serem responsabilizadas exclusivamente pelo seu sucesso ou fracasso profissional.

Outro aspecto a não ser negligenciado, e tratado por Saraiva (2005, p. 20), é o caráter inacabado das pesquisas sobre a competência profissional do professor: 
Assim como o cenário profissional, a própria configuração da competência profissional do professor é indefinida, imprecisa, mutante e variável, no tempo, no espaço e entre indivíduos. Definir e configurar a competência profissional do professor de LE, portanto, é tarefa sempre inacabada, imprecisa e imperfeita: um alvo móvel, que dificilmente será abatido em termos definitivos. Afinal, a cada mudança no contexto podem ocorrer alterações nos requisitos e nas expectativas.

Ser um professor reflexivo é procurar desenvolver o máximo de competências, questionando regularmente todas as suas práticas pedagógicas e, sobretudo, não desanimar diante das adversidades que parecem conspirar contra seu desempenho profissional a todo momento. Refletir demanda, acima de tudo, tempo. Tempo este que parece faltar ao professor de LE, que necessita muitas vezes conciliar atividades em escolas, cursos de idiomas e aulas particulares, de modo a manter sua sobrevivência. Como nos ensina Nóvoa (2007, p. 13):

há um outro paradoxo entre a retórica do professor reflexivo e, ao mesmo tempo, a inexistência de condições de trabalho concretas desde condições de tempo, a matéria-prima mais importante da reflexão - e desenvolvimento profissional que possam, de fato, alimentar a idéia do professor reflexivo. São paradoxos que precisamos saber ultrapassar e, para isso, é importante a mobilização, o combate coletivo dos professores.

\section{Considerações Finais}

O estudante de Letras - futuro professor de LE não pode se afastar da difícil realidade e dos desafios que se lhe apresentam. A rapidez com que mudam não apenas as abordagens no ensino de línguas, mas também o foco, com o surgimento de novos objetivos específicos, parece desafiar a todo momento esse estudante-professor que se sente, muitas vezes, despreparado pela universidade para enfrentar todas essas pressões do mercado. O treinamento profissional, técnico, que muitas vezes ele encontra apenas na prática de ensino e no estágio supervisionado, parece também não 
ser suficiente para prover a competência que lhe dará as armas necessárias àquela competição mercadológica a qual nos referimos anteriormente. Cabe às faculdades de Letras darem ao estudante a formação crítica necessária para que o futuro professor não se torne, por exemplo, um refém do mercado, transitando entre as pressões das casas editoriais, que fazem jorrar a cada ano material didático, que muitas vezes poucas inovações apresentam em relação aos anteriores. A mobilidade acadêmica crescente, por mais positiva que possa parecer, deve ser também questionada pelas faculdades de Letras num aspecto que particularmente lhes toca: os testes de proficiência. Muitas vezes as faculdades de Letras são vistas por outras unidades da própria universidade como potenciais aplicadoras desses testes, o que pode trazer o perigo de nos tornar, aos olhos de outras áreas, muito mais prestadores de serviço do que centros capacitadores e formadores de professores e pesquisadores.

O professor de línguas estrangeiras do novo século é alguém que deve estar consciente de todas essas questões aqui levantadas. As faculdades de Letras, até mesmo por razões de natureza curricular, talvez não consigam dar conta de toda essa formação cultural e técnica necessária aos novos profissionais. Nossos cursos não só partem de antemão desse aspecto binário língua-literatura, mas também precisam dar conta de muitas formações simultaneamente: língua e literatura vernácula, língua e literatura estrangeira, linguística, filologia, línguas clássicas. O que não se pode perder de vista é a formação crítica de nossos estudantes-futuros professores. Esse é o elemento que traça a linha divisória entre a mediocrização e a formação de professorespesquisadores conscientes, entre a unidade universitária meramente prestadora de serviços e a unidade formadora de intelectuais atentos, mas não subservientes ao mercado. Só esse profissional consciente poderá rejeitar ou pelo menos questionar o termo "instrutor de idiomas" que muitas vezes aparece em suas carteiras de trabalho, não apenas por conveniências trabalhistas, mas também por afirmação do senso comum, que reverencia um falante-nativo sem nenhuma formação profissional em Letras como o "professor ideal", em detrimento do estudante formado por nossas universidades. O aparelhamento crítico de nossos estudantes e futuros professores de línguas estrangeiras é, a nosso ver, o caminho mais eficaz a nosso alcance para a formação de profissionais transformadores e, por conseguinte, socialmente relevantes. 


\section{Referências}

ALBUQUERQUE COSTA, H. B.; MARINELLI, V. L. Formação inicial de professores de língua estrangeira: o ensino e a pesquisa no curso de letras francês da PUC-SP. Intercâmbio, São Paulo, v. 18, p. 94-106, 2008.

ALMEIDA FILHO, J. C. P. O professor de língua estrangeira sabe a língua que ensina? A questão da instrumentalização lingüística. Contexturas, São Paulo, v. 1, n. 1, p. 77-85, 1992.

ALMEIDA FILHO, J. C. P. Dimensões comunicativas no ensino de línguas. Campinas: Pontes, 1993.

BOURDIEU, P. Raisons pratiques: sur la théorie de l'action. Paris: Seuil, 1994.

BOURDIEU, P. Ce que parler veut dire: l'économie des échanges linguistiques. Paris: Fayard, 1982.

BRASIL. Decreto-lei n. 4.244, de 9 de abril de 1942. Lei orgânica do ensino secundário. Diário Oficial da União, Rio de Janeiro, DF, 10 abr. 1942. Seção I, p. 5.798. Disponível em: <http://bit.do/cSE7z>. Acesso em: 08 maio 2015.

BRASIL. Lei n. 4.024, de 20 de dezembro de 1961. Fixa as diretrizes e bases da educação nacional. Diário Oficial da União, Brasília, DF, 27 dez. 1961. Seção I, p. 11.429. Disponível em: < http://bit.do/cSE7B>. Acesso em: 08 maio 2015.

BRASIL. Lei n. 9.394, de 20 de dezembro de 1996. Estabelece as diretrizes e bases da educação nacional. Diário Oficial da União, Brasília, DF, 23 dez. 1996. Seção I, p. 27.834. Disponível em: < http://bit.do/cSE7X>. Acesso em: 10 maio 2015.

BRASIL. Lei n. 11.161, de 5 de agosto de 2005. Dispõe sobre o ensino de língua espanhola. Diário Oficial da União, Brasília, DF, 8 ago. 2005. Seção I, p. 1. Disponível em: <http://bit.do/cSE8c>. Acesso em: 08 maio 2015. 
BRASIL. Parâmetros Curriculares Nacionais: terceiro e quarto ciclos do ensino fundamental - língua estrangeira. Brasília: MEC; SEF, 1998.

CALVET, L.-J. Le marché aux langues: les effets linguistiques de la mondialisation. Paris: Plon, 2002.

CHAGAS, V. Didática especial de línguas modernas. São Paulo: Companhia Editora Nacional, 1957.

CONSOLO, D. A.; MARTINS, M. J.; ANCHIETA, P. P.

Desenvolvimento de habilidades orais em língua inglesa no curso de letras: uma experiência. Em Aberto, Brasília, v. 22, p. 31-45, 2009.

CONSOLO, D. A.; PORTO, C. F. C. Competências do professor no processo de ensino-aprendizagem de língua estrangeira. Horizontes de Linguística Aplicada, Brasília, a. 10, n. 2, p. 65-85, jul./dez. 2011.

DEWEY, J. Como pensamos. São Paulo: Companhia Editora Nacional, 1959.

LEFFA, V. J. O professor de línguas estrangeiras: do corpo mole ao corpo dócil. In: FREIRE, M. M.; ABRAHÃO, M. H. V.; BARCELOS, A. M. F. (Org.). Lingüistica Aplicada e contemporaneidade. São Paulo: ALAB; Pontes, 2005. p. 203-218.

MARCUSCHI, L. A. A formação intelectual do estudante de Letras. In: MOLLICA, M. C. Linguagem para a formação em letras, educação e fonoaudiologia. São Paulo: Contexto, 2009. p. 9-18.

MOITA LOPES, L. P. Oficina de Lingüistica Aplicada: a natureza social e educacional dos processos de ensino-aprendizagem de línguas. Campinas: Mercado de Letras, 1996.

NÓVOA, A. Desafios do professor no mundo contemporâneo. São Paulo:

SINPRO-SP, 2007. Disponível em: < http://bit.do/cSE8s>. Acesso em: 10 abr. 2015.

PARPETTE, C.; MANGIANTE, J.-M. Le Français sur objectif universitaire. Grenoble: PUG, 2011. 
PENNYCOOK, A. The cultural politics of English as an international language. London: Longman, 1994.

PERRENOUD, P. 10 novas competências para ensinar. Porto Alegre: Artmed, 2000.

SANDEI, M. L. R. Prospeç̧ões sobre a abordagem/senso de plausibilidade na ação de ensinar de um professor de língua estrangeira no ensino médio. 2005. Dissertação (Mestrado em Linguística Aplicada) - Universidade Estadual de Campinas, Campinas.

SARAIVA, P. S. Requisitos e expectativas na construção da competência profissional de ensinar LE. 2005. Dissertação (Mestrado em Linguística Aplicada) Universidade de Brasília, Brasília.

SCHÖN, D. A. Formar professores como profissionais reflexivos. In: NÓVOA, A. (Coord). Os professores e a sua formação. Lisboa: Dom Quixote, 1997. p. 79-91.

SILVA, C. C.; ZEULLI, E. O professor reflexivo no processo de ensino aprendizagem de língua estrangeira. Triângulo, Uberaba, v. 3, n. 1, p. 47-55, jan./jun. 2010.

UNESCO/PEN-CLUB Internacional. Declaração Universal dos Direitos Lingüisticos. Barcelona, jun. 1996. Disponível em: < http://bit.do/cSE8B>. Acesso em: 20 abr. 2015.

Recebido em: 28/05/2015

Aceito: $17 / 04 / 2016$ 